\title{
Induction of the intrinsic apoptotic pathway via a new antimitotic agent in an esophageal carcinoma cell line
}

\author{
Elize Wolmarans ${ }^{1}$, Katherine Sippel ${ }^{2}$, Robert McKenna ${ }^{3}$ and Annie Joubert ${ }^{1 *}$
}

\begin{abstract}
Background: 2-Ethyl-3-O-sulphamoyl-estra-1,3,5(10)16-tetraene (ESE-16) is a unique, in silico-designed compound with possible anticancer properties, which were identified in our laboratory. This compound is capable of interfering with microtubule dynamics and is believed to have potential carbonic anhydrase IX inhibiting activity. In this study, it was investigated whether ESE-16 is capable of inducing apoptosis in vitro in the esophageal carcinoma SNO cell line via the intrinsic pathway at a concentration of $0.2 \mu \mathrm{M}$ with an exposure time of 24 hours.

Results: Qualitative results were obtained via light microscopy, transmission electron microscopy and confocal microscopy. Results showed hallmarks of apoptosis in the ESE-16-treated cells. In addition, data revealed an increase in the number of ESE-16-treated cells blocked in metaphase. Cell death via apoptosis in the ESE-16-treated cells was confirmed by studying the internal ultrastructure of the cells via transmission electron microscopy, while confocal microscopy revealed abnormal spindle formation and condensed chromatin in ESE-16-treated cells, thus confirming metaphase block.

Quantitative results were obtained via flow cytometry and spectrophotometry. Cell death via apoptosis in ESE-16-treated cells was quantitatively confirmed by the Annexin V-FITC apoptosis detection assay. Flow cytometry and spectrophotometry revealed dissipation of mitochondrial membrane potential and an increase in superoxide levels in the ESE-16-treated cells when compared to the relevant controls. Both initiator caspase 9 and effector caspase 3 activities were increased, which demonstrates that ESE-16 causes cell death in a caspase-dependent manner.

Conclusions: This was the first in vitro study conducted to investigate the action mechanism of ESE-16 on an esophageal carcinoma cell line. The results provided valuable information on the action mechanism of this potential anticancer agent. It can be concluded that the novel in silico-designed compound exerts an anti-proliferative effect on the esophageal carcinoma SNO cell line by disrupting microtubule function resulting in metaphase block. This culminates in apoptotic cell death via the intrinsic apoptotic pathway. This research provided cellular targets warranting in vivo assessment of ESE-16's potential as an anticancer agent.
\end{abstract}

Keywords: 2-Ethyl-3-O-sulphamoyl-estra-1,3,5(10)16-tetraene, Esophageal carcinoma, Intrinsic apoptotic pathway

\section{Background}

Microtubule-interfering drugs (MIDs) are one of the most promising classes of cancer chemotherapeutic drugs available [1-3]. MIDs target the cell cycle by binding to and interfering with the microtubule machinery, thereby inhibiting the normal function of the mitotic spindle and preventing hyperproliferation of cancer cells [1,4-6]. Owing

\footnotetext{
*Correspondence: annie.joubert@up.ac.za

'Department of Physiology, University of Pretoria, Pretoria, South Africa Full list of author information is available at the end of the article
}

to the therapeutic success of MIDs, intense search and development for new microtubule-targeting compounds are being conducted by pharmaceutical companies [2].

2-Methoxyestradiol (2ME) (Figure 1A) is an endogenous metabolite derived from 17 $\beta$-estradiol [6-12] with antiproliferative, anti-angiogenic and pro-apoptotic characteristics in vitro and in vivo $[6-8,13,14]$ independent of estrogen receptors $[6,12,15,16]$. 2ME's major target is the microtubule skeleton $[6,7,11,12,14,16]$. The compound influences the spindle assembly checkpoint (SAC) by interacting with the colchicine binding site situated between the $\alpha$ - and 

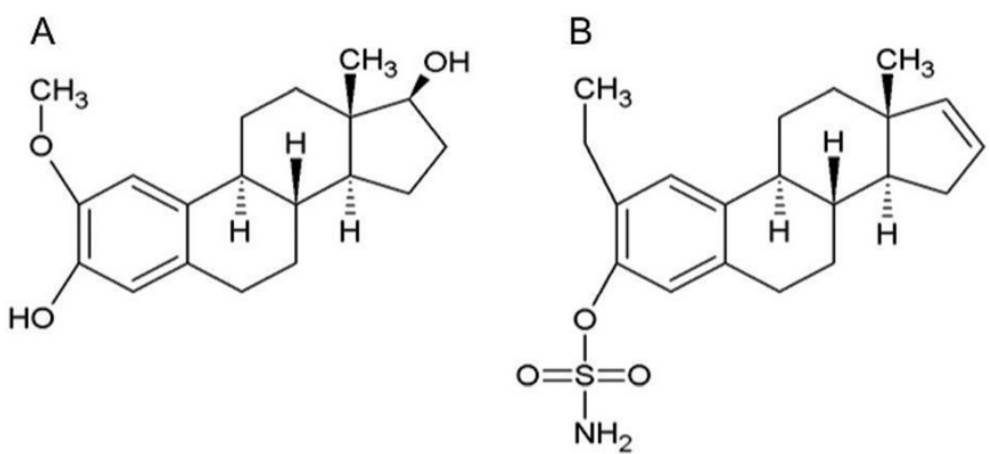

Figure 1 Structural comparison between (A) 2ME and (B) ESE-16. When the two chemical structures are compared, an exchange of a sulphamoylated group for a hydroxyl group at position 3 and the removal of a hydroxyl group at position 17 on the ESE-16 compound are noticed. The sulphamoylated group increases the bioavailability of the compound $[8,13,20,28,29]$, while the modifications at position 3 and -17 increases the anticancer potency and provides a prolonged half-life $[6,11,13,22,27,28]$.

$\beta$-dimers of the tubulin protein $[8,9,14,17,18]$. This interaction causes abnormal spindle formation and activation of the spindle checkpoint, which leads to metaphase arrest, inhibition of further cell proliferation and the induction of cell death $[6,10,11,19]$.

$2 \mathrm{ME}$, however, has been found to have low bioavailability in the human body as a result of rapid metabolic degradation by the enzyme $17 \beta$-hydroxysteroid dehydrogenase type 2 in the gastrointestinal tract and liver [8,13,20-22]. The compound is registered as "Panzem" by Entremed Inc. (Rockville, Maryland, USA) and is currently undergoing clinical trials with an innovative nanocrystal dispersion (NCD) drug delivery system which may possibly overcome the rapid biodegradation problem [23-26].

Researchers have attempted to create analogues of $2 \mathrm{ME}$ with improved bioavailability and potency. The analogue being investigated in this research was the latest in silicodesigned 2ME derivative: 2-ethyl-3-O-sulphamoyl-estra1,3,5(10)16-tetraene (ESE-16). ESE-16 (Figure 1B) was developed when potential carbonic anhydrase IX (CAIX) inhibitors, capable of interfering with microtubule dynamics were identified in our laboratory with the use of bioinformatics software [8].

When the chemical structures of ESE-16 and 2ME are compared (Figure 1), an exchange of a sulphamoylated group for a hydroxyl group at position 3 and the removal of a hydroxyl group at position 17 on the ESE-16 compound are noticed. Previous studies have shown sulphamoylated analogues with modifications on the 3- and 17-position of the molecule revealed significant anticancer potency and prolonged half-life and bioavailability $[6,11,13,22,27,28]$. Increased bioavailabilty is due to the ability of the sulfamoylated derivatives to reversibly bind to carbonic anhydrase II (CAII) found in red blood cells, thereby enabling them to journey through the liver without undergoing presystemic metabolism $[8,13,20,28,29]$.
Our laboratory has demonstrated the anti-proliferative action of ESE-16 in a variety of cell lines: the tumorigenic human epithelial cervical HeLa cell line, MCF-7 breast cancer cell line, esophageal carcinoma SNO cell line, metastatic MDA-MB-231 breast cancer cell line and the non-tumorigenic MCF-12A cell line [8,29-32].

Studies have also revealed ESE-16 to be more potent than its source compound, 2ME [8]. Research has shown that 2ME exerts antiproliferative effects at concentrations between 1-2 $\mu \mathrm{M}$, whereas ESE-16 has shown antiproliferative activity at nanomolar values, with a $\mathrm{GI}_{50}$ value of $180-220 \mathrm{nM}$ [8].

The exact action mechanism of ESE-16, however, still remains to be elucidated. This in vitro study was the first to investigate the action mechanism of ESE-16 on an esophageal carcinoma cell line.

It was hypothesized that ESE-16 uses the intrinsic apoptotic pathway as an action mechanism to cause cell death. In the hypothesized chain of events the compound binds to the microtubules of the esophageal carcinoma cells, causing the activation of the SAC and subsequent metaphase arrest. This leads to increased reactive oxygen species (ROS) production, mitochondrial membrane potential $(\Delta \Psi \mathrm{m})$ dissipation, degradation of the mitochondrial membrane and the release of cytochrome $c$. Cytochrome $c$ then binds with apoptotic protease activating factor 1 (Apaf-1) to form the apoptosome, which activates the initiator caspase 9. Caspase 9 activates the effector caspase 3, which then leads to the cell undergoing apoptosis.

The results provided valuable information on the action mechanism of this potential anticancer agent. It can be concluded that the novel in silico-designed compound exerts an anti-proliferative effect on the esophageal carcinoma SNO cell line by disrupting microtubule function, resulting in metaphase block. This culminates in apoptotic cell death via the intrinsic apoptotic pathway. 


\section{Results}

Haematoxylin and eosin staining show morphological changes in the ESE-16-treated SNO cells

Haematoxylin and eosin (H\&E) staining allows for the quantitative comparison of the morphological characteristics of the cytoplasm and nuclear components of the cells [10]. The staining was used to visualize morphological changes in SNO cells after exposure to ESE-16 and the appropriate controls. Cells propogated in medium (Figure 2A) and the vehicle control (Figure 2B) showed normal cell morphology with the majority of the cells being in interphase. The positive control for apoptosis (Figure 2C) and ESE-16-treated cells (Figure 2D) showed a decrease in cell density and morphological characteristics of apoptosis such as membrane blebbing and apoptotic bodies. ESE-16-treated cells also showed an increase in the number of round cells with hypercondensed chromatin indicative of metaphase block.

In order to obtain quantitative data from this morphological study, mitotic indices were determined (Table 1) [10]. One thousand cells were counted on each slide of the biological replicates and divided into their different phases [10,33]. Identification of cells in interphase, the different mitotic phases and cells undergoing apoptosis were done based on their cellular and nuclear morphology [34]. Cells that could not be categorized as a result of excessive fragmentation, unusual nuclear morphology or a lack of clear nuclear material were defined and counted as abnormal [11]. The data is expressed as percentages of cells in each phase. Mitotic indices revealed
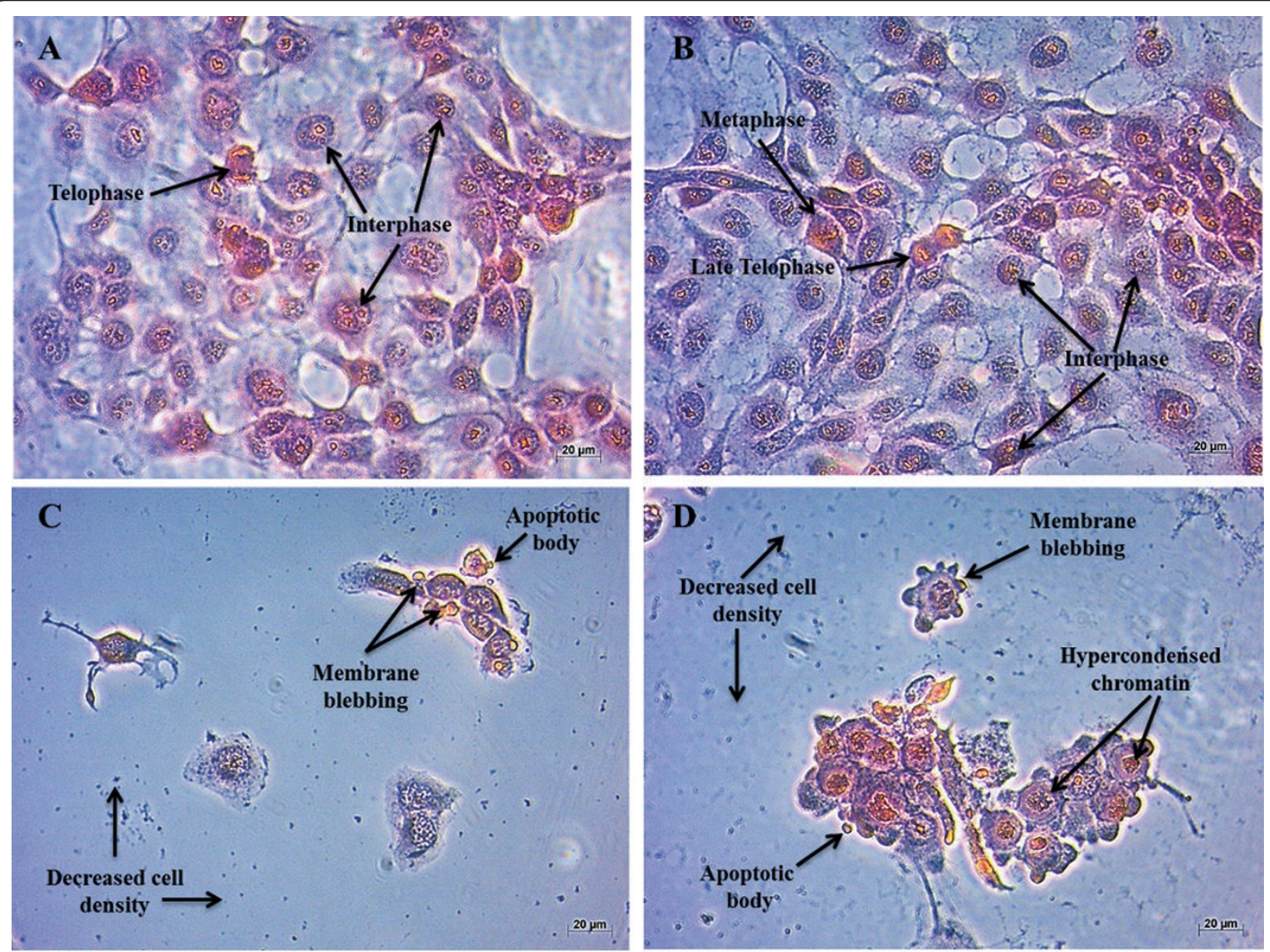

Figure 2 Haematoxylin and eosin staining images revealing morphological changes in the nuclear and cytoplasmic components in SNO cells. (A) Cells propogated in medium only, (B) cells exposed to dimethyl sulphoxide (DMSO) - vehicle control, (C) cells exposed to actinomycin D - positive control and (D) cells exposed to ESE-16 at a concentration of $0.2 \mu \mathrm{M}$. Cells propogated in medium and the vehicle-treated cells showed normal cell morphology, with the majority of the cells being in interphase. The positive control for apoptosis and the ESE-16 treated cells showed a decrease in cell density and morphological characteristics of apoptosis such as membrane blebbing and apoptotic bodies. The ESE-16 treated cells also showed an increase in the number of round cells with hypercondensed chromatin indicative of a metaphase block (Magnification: ×20). 
Table 1 Average percentage of cells in interphase, various stages of mitosis and cells displaying apoptotic morphology

\begin{tabular}{llllllll}
\hline & Interphase & Prophase & Metaphase & Anaphase & Telophase & Apoptosis & Abnormal \\
\hline Medium & $96.1 \%$ & $0.6 \%$ & $1.5 \%$ & $0.4 \%$ & $0.6 \%$ & $0.5 \%$ & $0.4 \%$ \\
DMSO & $97.5 \%$ & $0.2 \%$ & $1.3 \%$ & $0.2 \%$ & $0.6 \%$ & $0.2 \%$ & $0.4 \%$ \\
Actinomycin D & $60.2 \%$ & $0.3 \%$ & $2.5 \%$ & $0 \%$ & $0.5 \%$ & $33.8 \%$ & $2.3 \%$ \\
ESE-16 & $27.3 \%$ & $0.7 \%$ & $46.0 \%^{*}$ & $0.2 \%$ & $0.4 \%$ & $21.4 \%^{*}$ & $4.2 \%$ \\
\hline
\end{tabular}

Mitotic indices revealed a significant increase, with a P-value of $0.0003^{*}$, in the percentage of cells in metaphase in the ESE-16-treated samples (46.0\%) when compared to the vehicle control (1.3\%). ESE-16-treated cells also showed a significant increase (P-value of $0.0006^{*}$ ) in the percentage of cells undergoing apoptosis (21.4\%) when compared to the vehicle control $(0.2 \%)$.

a significant increase, with a $P$-value of $0.0003^{*}$, in the percentage of cells in metaphase in the ESE-16-treated samples when compared to controls. ESE-16-treated cells also showed a significant increase in the percentage of cells undergoing apoptosis when compared to the appropriate controls ( $P$-value of 0.0006$)$.
Transmission electron microscopy shows changes in the internal ultrastructure of the ESE-16-treated SNO cells Transmission electron microscopy (TEM) was used to study the internal ultrastructure of the SNO cells after exposure to ESE-16 and the appropriate controls. Results revealed normal infrastructure of cells propogated in
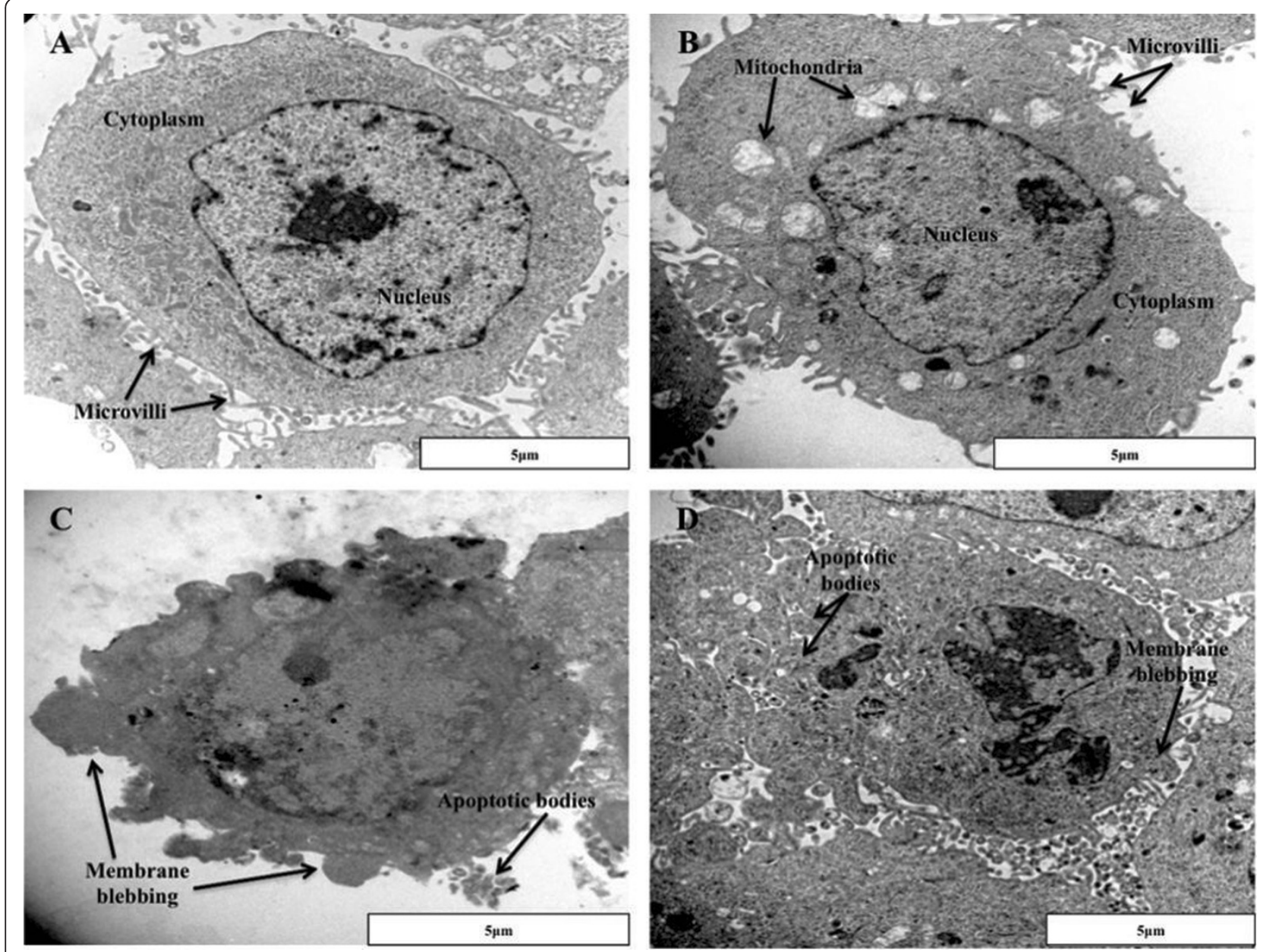

Figure 3 Transmission electron microscopy images providing information on the internal ultrastructure of SNO cells propogated in medium only and SNO cells treated with DMSO. (A) Cells propogated in medium only, (B) cells exposed to DMSO - vehicle control, (C) cells exposed to actinomycin D - positive control and (D) cells exposed to ESE-16 at a concentration of $0.2 \mu \mathrm{M}$. Both the cells propogated in medium and the vehicle control cells showed microvilli protruding from their cell membrane surface. The nuclear membrane is smoothly outlined and well-preserved cytoplasmic organelles are visible. The positive control for apoptosis showed loss of microvilli, membrane blebbing and the presence of apoptotic bodies. ESE-16-treated cells revealed a decrease in nuclear membrane definition, membrane blebbling and apoptotic body formation. Scale bar: $5 \mu \mathrm{m}$. 
medium (Figure 3A) and in the vehicle control (Figure $3 \mathrm{~B}$ ). Both the cells propogated in medium and the vehicle control revealed microvilli protruding from their cell membrane surface, a smoothly outlined nuclear membrane and well-preserved cytoplasmic organelles. The positive control for apoptosis (Figure 3C) showed loss of microvilli, membrane blebbing and the presence of apoptotic bodies. An ESE-16-treated cell image (Figure 3D) revealed a decrease in nuclear membrane definition, membrane blebbling and apoptotic body formation.

\section{Confocal microscopy reveals the effect ESE-16 has on the} microtubule architecture of the SNO cells

Confocal microscopy was used to determine the influence of ESE-16 on the cytoskeletal microtubule architecture of
SNO cells after exposure to ESE-16 and the appropriate controls. Cells were stained with mouse monoclonal antibody against human $\alpha$-tubulin and a secondary antibody, biotin-conjugated anti-mouse IgG 58 (Fab-specific, developed in goat) in a fluorescein isothiocyanate (FITC)-conjugate diluent, which stained the $\alpha$-tubulin of the cells green. 4',6-Diamidino-2-phenylindole (DAPI) was used to stain the nuclei of the cells blue to provide contrast to the green stain. Cells propogated in medium (Figure 4A) and vehicle control cells (Figure 4B) showed normal microtubule architecture. The positive control (Figure 4C) showed a decrease in cell density and revealed shrunken cells. The ESE-16-treated cells (Figure 4D) also showed a decrease in cell density and revealed abnormal spindle formation, indicating cells being blocked in metaphase.
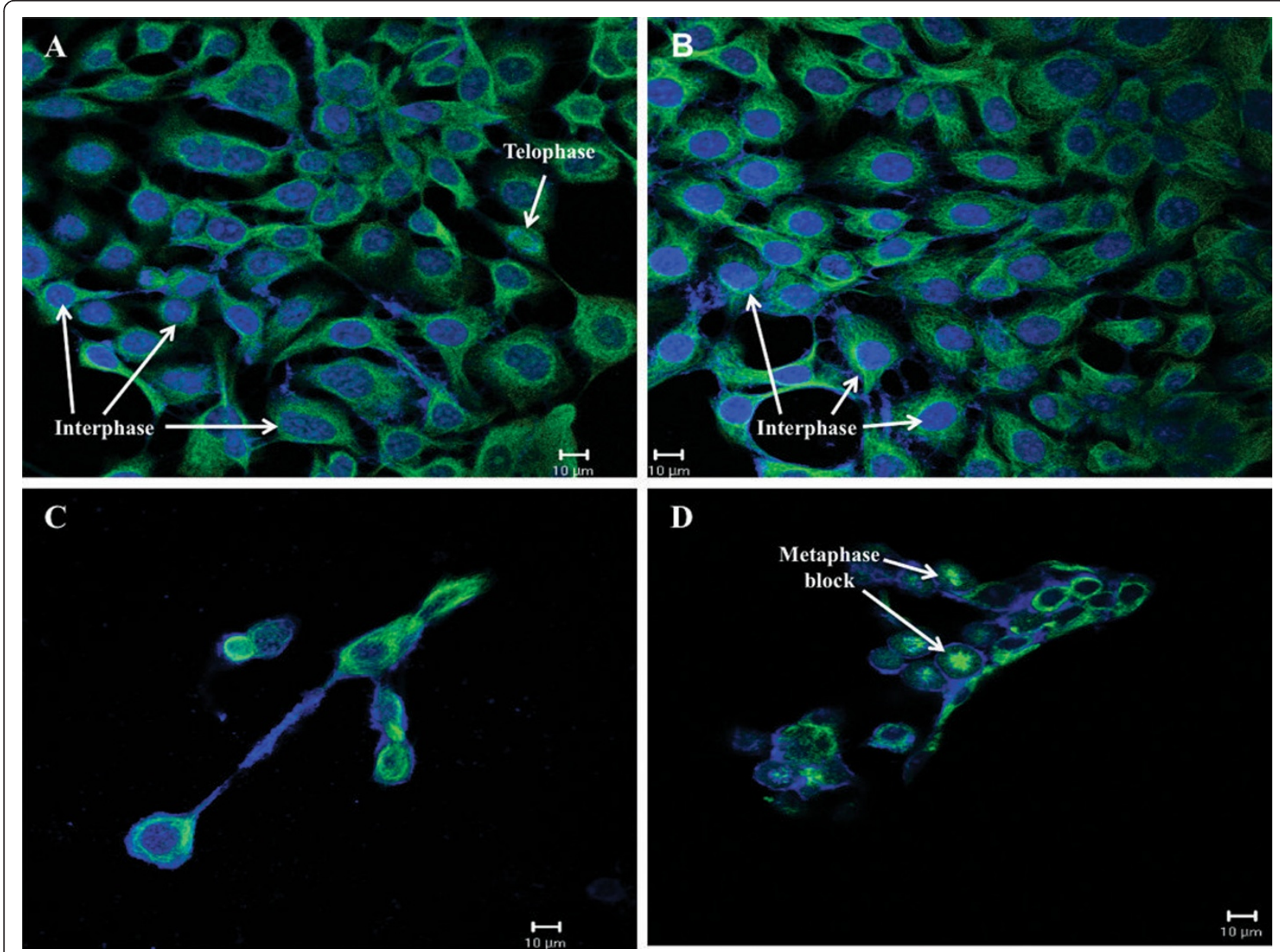

Figure 4 Confocal microscopy images of the microtubule architecture of SNO cells with the use of anti-a tubulin antibodies and nuclear stain 4',6-diamidino-2-phenylindole. (A) Cells propogated in medium only, (B) cells exposed to DMSO - vehicle control, (C) cells exposed to actinomycin D - positive control and (D) cells exposed to ESE-16 at a concentration of $0.2 \mu \mathrm{M}$. The a-tubulin of the cells were stained green by a FITC-conjugate diluent while the nuclei were stained blue by DAPI to provide contrast to the green fluorescence. Cells propogated in medium and vehicle control cells showed normal microtubule architecture. The positive control showed a decrease in cell density and revealed shrunken cells. ESE-16-treated cells showed a decrease in cell density and abnormal spindle formation when compared to the appropriate controls. The abnormal spindle formation is indicative of metaphase block. Scale bar: $10 \mu \mathrm{m}$. 


\section{Apoptosis induction in the ESE-16-treated SNO cells}

Annexin V-FITC, a well-known apoptosis-detecting assay, was used to confirm that apoptosis was taking place in the SNO cells after exposure to ESE-16 (Figure 5). Results revealed an average increase in the mean fluorescent intensity (MFI) in the ESE-16-treated cells (average of 25.50) when compared to the vehicle control with an average MFI of 11.32. The increase in MFI indicates an increase in phosphatidylserine (PS) externalization, which is an early apoptotic indicator [35]. The $P$-value obtained for this experiment, however, was 0.0614 , which is statistically insignificant. The statistically insignificant increase may be due to the fact that PS externalization is an early sign of apoptosis and that, at the time of experiment termination, the cells may have already surpassed the early apoptotic stage. This may also explain the low MFI value of the positive control (average of 18.82).

\section{Decrease in mitochondrial membrane potential in ESE-16-treated SNO cells}

The Mitotracker Kit was used to study the possible influence ESE-16 has on the $\Delta \Psi \mathrm{m}$ of the SNO cells. The mitochondria are labeled by a cationic dye named “5,5',6,6'-tetrachloro-1,133'-tetra-ethylbenzimidazolylcarbocyanine iodide", which passively diffuses across the plasma membrane and accumulates in active mitochondria [36]. Reduction of the $\Delta \Psi \mathrm{m}$ is another feature of apoptosis that is due to the loss of the electrochemical gradient across the mitochondrial membrane. With the reduction of the $\Delta \Psi \mathrm{m}$, the mitotracker dye cannot aggregate in the mitochondria and thus remains in the cytoplasm in its monomer form, generating green fluorescence [36].

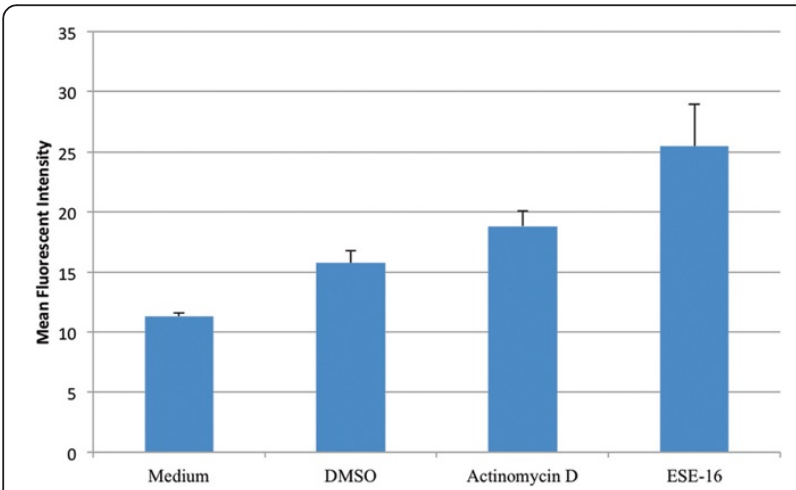

Figure 5 Bar graph showing the average mean fluorescent intensity increase in the ESE-16-treated cells compared to the appropriate controls illustrating an increase in

phosphatidylserine externalization. This bar graph represents the average MFI of all three repeats done. Cells propogated in medium had an average MFI of 11.31, the vehicle control had an average MFI of 15.74, the positive control had an average MFI of 18.82 while the ESE-16-treated cells an average MFI of 25.50. The increased MFI indicates an increase in PS externalization which is an early apoptotic indicator [35].
Results obtained showed a statistcally significant $(P$-value of 0.019)" increase in the MFI of green fluorescence in the ESE-16-treated cells when compared to the appropriate controls (Figure 6). These results demonstrate the ability of ESE-16 to cause a decrease in $\Delta \Psi \mathrm{m}$. These findings confirm the qualitative and quantitative data obtained with regard to ESE-16 causing apoptosis at a concentration of $0.2 \mu \mathrm{M}$ after an exposure time of 24 hours. The results also provide evidence of the degradation of the mitochondrial membrane, indicating apoptotic cell death via the intrinsic pathway.

\section{Increase in superoxide levels in ESE-16-treated SNO cells}

The accumulation of ROS may lead to oxidative damage to mitochondrial proteins and mitochondrial deoxyribonucleic acid (DNA), causing loss of electron transport, decrease in adenosine triphosphate (ATP) production and $\Delta \Psi \mathrm{m}$ dissipation [37-40]. Superoxide anion $\left(\mathrm{O}_{2}{ }^{-}\right)$ can be regarded as the precursor for most ROS [40]. Thus, flow cytometry was used to measure $\mathrm{O}_{2}{ }^{-}$levels in the SNO cells after exposure to ESE-16 and the various controls (Figure 7).

Viable cells represent the population of cells that showed little or no increase in fluorescence, thus no increase in $\mathrm{O}_{2}^{-}$production. Non-viable cells represent the population of cells with an increase in fluorescence, thus indicating an increase in $\mathrm{O}_{2}{ }^{-}$production. Results revealed an increase in $\mathrm{O}_{2}{ }^{-}$production in the ESE-16 treated cells with $38.17 \%$ of its population being nonviable when compared to the $21.45 \%$ non-viable population of the vehicle control (Table 2). Results indicate that

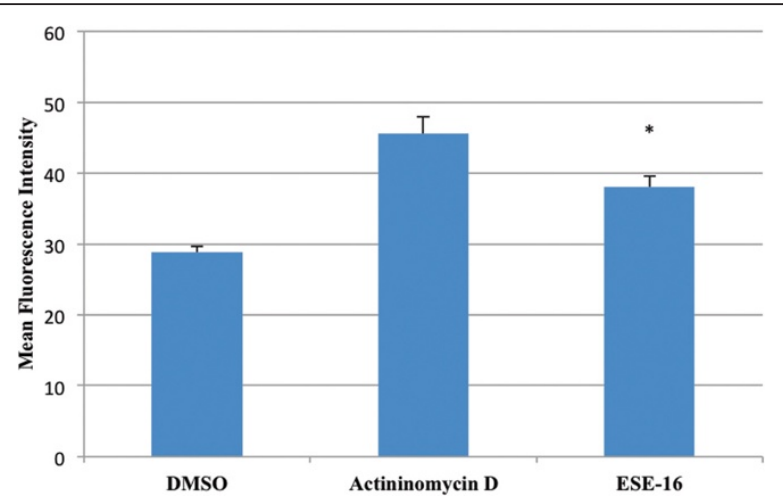

Figure 6 Bar graph showing the average mean fluorescent intensity increase in the ESE-16-treated cells compared to the appropriate controls, illustrating a decrease in mitochondrial membrane potential. This bar graph represents the average MFI of all three repeats done. The vehicle control had an average MFI of 28.79 while the postive control had an average MFI of 45.58 and the ESE-16-treated cells an average MFI of 37.995. The increase in the MFI seen in the ESE-16-treated cells is statistically significantly ( $P$-value of 0.019$)^{*}$ higher than that of the vehicle control indicating a decrease in $\Delta \Psi \mathrm{m}$ and possible mitochondrial membrane degradation. 

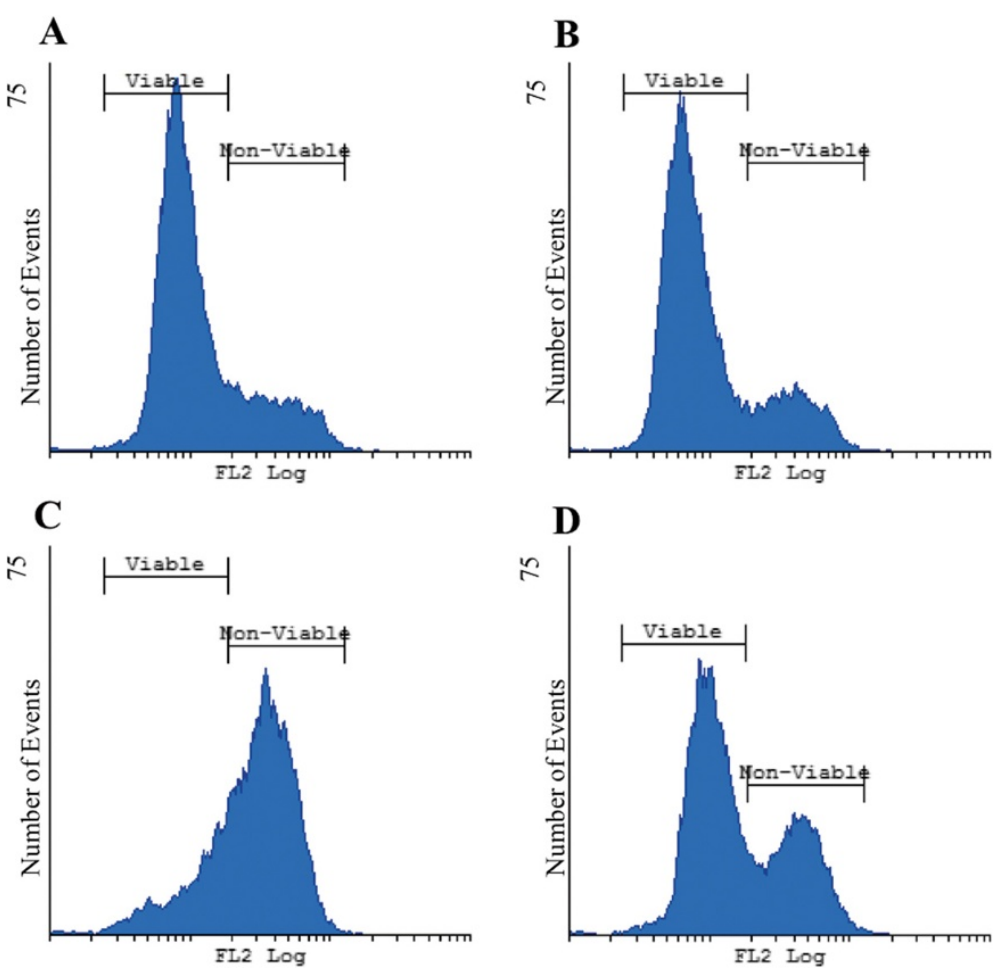

Figure 7 Histograms illustrating superoxide levels in SNO cells after exposure to ESE-16 and the appropriate controls of a representative repeat. (A) Cells propogated in medium only, (B) cells exposed to DMSO - vehicle control, (C) cells exposed to actinomycin D - positive control and (D) cells exposed to ESE-16 at a concentration of $0.2 \mu \mathrm{M}$. Viable cells represent the population of cells which showed little or no increase in fluorescence, thus no increase. The non-viable cells represent the population of cells with an increase in fluorescence thus indicating an increase in $\mathrm{O}_{2}{ }^{-}$production. The ESE-16-treated cells showed $38.17 \%$ of its population to be non-viable compared to the $21.45 \%$ non-viable population of the vehicle control.

ESE-16 does cause an increase in $\mathrm{O}_{2}{ }^{-}$levels, which may lead to mitochondrial degradation and cell death. This confirms results obtained from studying the $\Delta \Psi \mathrm{m}$.

\section{Increase in caspase activity in the ESE-16-treated SNO cells}

The activity of initiator caspase 9 and the effector caspase 3 in SNO cells after exposure to ESE-16 or the appropriate controls was studied via spectrophotometry. Results, showing the average ratio to medium, revealed an increase in both caspase 9 and caspase 3 activity in the ESE-16treated cells when compared to the vehicle control.

The initiator caspase 9 results (Figure 8) showed that ESE-16-treated cells had a ratio to medium value of 1.2188 , while the vehicle control had a value of 1.0625 .

Table 2 Percentages of viable and non-viable cells of the representative repeat, illustrating superoxide levels in SNO cells after exposure to ESE-16 and the appropriate controls

\begin{tabular}{lllll}
\hline & Medium & DMSO & Actinomycin D & ESE-16 \\
\hline Viable cells & $75.18 \%$ & $77.90 \%$ & $22.61 \%$ & $60.11 \%$ \\
Non-viable cells & $23.45 \%$ & $21.05 \%$ & $75.29 \%$ & $38.17 \%$ \\
\hline
\end{tabular}

This is not a statistically significant increase ( $P$-value of 0.238 ) when compared to the difference in caspase 3 ratio to medium values. The effector caspase 3 results (Figure 9) showed ESE-16-treated cells had an average ratio to medium value of 2.9772 while the vehicle control had a value of 1.0681 . This is a statistically significant increase, with a $P$-value of $0.004 \%$.

The difference in the increase of activity of the two caspases may be explained by the fact that the effector caspase 3 had already, at the time of measurement, begun the degradation phase of apoptosis [35,41], causing a decrease in caspase 9 levels. The caspase activity results show that ESE-16 causes the activation of caspases and reveals that ESE-16 causes cell death in a caspase-dependent manner.

\section{Discussion}

ESE-16, a unique, in silico-designed compound was designed with the dual capability of interfering with microtubule dynamics [1] and inhibiting CAIX, which is overexpressed in a variety of tumours $[8,42]$. These two targets were chosen because: 1) several studies have shown that inhibition of CAIX can lead to decreased 


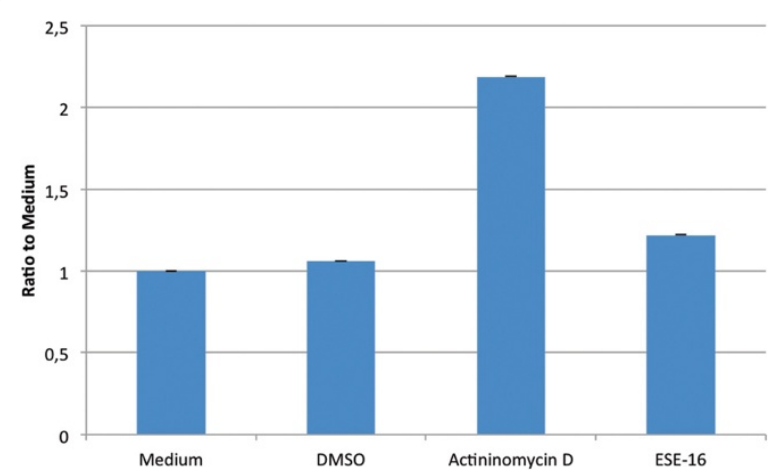

Figure 8 Bar graph illustrating the ratio to medium of the initiator caspase 9 levels in SNO cells exposed to ESE-16 and various controls. Results revealed a statistically insignificant increase ( $P$-value of 0.238 ) in caspase 9 activity in the ESE-16-treated cells when compared to the vehicle control. The ESE-16-treated cells had a ratio to medium value of 1.2188 , while the vehicle control had a ratio to medium value of 1.0625

invasiveness and may cause cell death under hypoxic conditions [42] and 2) by binding to microtubules there is interference during cell division, which may lead to cell death [1,4-6].

In this study ESE-16 was shown to induce apoptosis in vitro in the esophageal carcinoma SNO cell line via the intrinsic pathway at a concentration of $0.2 \mu \mathrm{M}$ with an exposure time of 24 hours. The concentration of $0.2 \mu \mathrm{M}$ for ESE-16 was chosen since previous dosedependent investigations conducted in our laboratory showed ESE-16 inhibiting cell proliferation to 50\% from concentrations ranging from $0.18 \mu \mathrm{M}$ to $0.22 \mu \mathrm{M}$ [8].

Qualitative results were obtained via H\&E staining, TEM and confocal microscopy and provided information on morphological changes, microtubule architecture and internal ultrastructures of the SNO cells after exposure to ESE-16. The H\&E results revealed the presence of apoptotic morphological characteristics, such as membrane blebbing and apoptotic bodies in the ESE16-treated. These results were confirmed by studying the internal ultrastructure of the cells via TEM. Results revealed lack of definition of the nuclear membrane, membrane blebbling and apoptotic body formation in the ESE-16-treated cells when compared to the appropriate controls.

Apoptosis occuring in ESE-16-treated SNO cells were studied quantitatively via mitotic indices and the Annexin V-FITC apoptosis-detection assay. Mitotic indices quantified the observed effects in the H\&E staining images and revealed a statistically significant increase ( $P$-value of 0.0006) "in the percentage of ESE-16-treated cells undergoing apoptosis when compared to the appropriate controls. Results from the Annexin V-FITC apoptosis-detection assay revealed a statistically insignificant increase in MFI ( $P$-value of 0.0614$)$ of the ESE-16-treated cells when

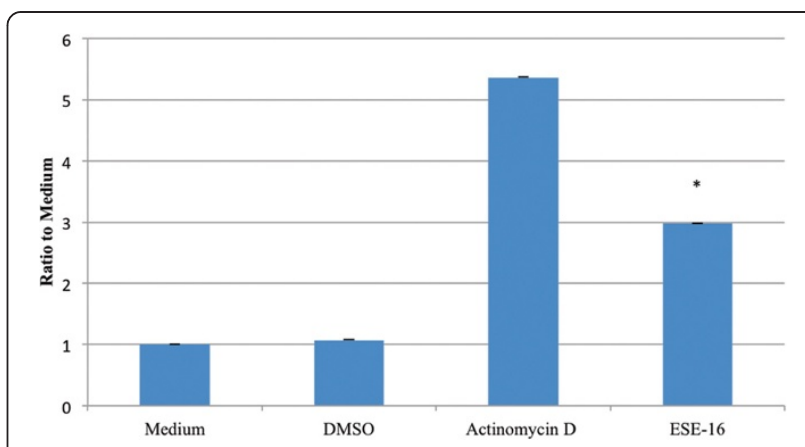

Figure 9 Bar graph illustrating the ratio to medium of the effector caspase 3 levels in SNO cells exposed to ESE-16 and various controls. Results revealed a statistically significant increase $(P \text {-value of } 0.004)^{*}$ in caspase 3 activity in the ESE-16-treated cells when compared to the vehicle control. The ESE-16-treated cells had a ratio to medium value of 2.9772 , while the vehicle control had a ratio to medium value of 1.0681 .

compared to the appropriate controls. The increased MFI indicates an increase in PS externalization, which is an early apoptotic indicator [35]. The insignificant increase in MFI may be ascribed to the fact that at the time of experimental termination, the cells may have already surpassed the early apoptotic stage. When combined with the qualitative and quantitative results obtained via mitotic indices, H\&E staining and TEM, a relationship between ESE-16 exposure and apoptosis can be observed. In addition, the authors have previously demonstrated that the ESE-16 compound induces apoptosis in the esophageal carcinoma cell line with propidium iodide inclusion [32]. In the article by Wolmarans et al. cell cycle analysis was performed to study the influence of ESE-16 on the cell cycle progression of the SNO cell line. An increase in the percentage of cells in the sub $G_{1}$ (indicative of apoptosis) in the ESE-16-treated cells was observed when compared to the relevant controls [32].

These results correlates with the findings of Nkandeu et al., who tested ESE-16 on MCF-7 breast carcinoma cell line [31]; Theron et al., who tested ESE-16 on the tumorigenic human epithelial cervical HeLa cell line [30] and Stander et al. who tested ESE-16 on the tumorigenic MCF-7, the metastatic MDA-MB-231 and the non-tumorigenic MCF-12A breast cancer cells [29].

In a comparison of ESE-16 and 2ME's ability to induce cell death, similarities exist. The effects of $2 \mathrm{ME}$ have been studied on various cell lines, including the MCF-7 cell line, the estrogen receptor-negative breast carcinoma cell line MDA-MB-435, the human ovarian adenocarcinoma cell line OVCAR-3 and the renal carcinoma cell line SN12-C [43]. Du et al. studied the effects of $2 \mathrm{ME}$ on the esophageal carcinoma EC9706 cell line in a timeand dose-dependent study and showed an increase in apoptosis in the 2ME-treated cells after 24 hours at concentrations of $5 \mu \mathrm{M}$ and $10 \mu \mathrm{M}$ [7]. Cell death via apoptosis and due to $2 \mathrm{ME}$ exposure was also found by 
Stander et al. and Thaver et al. when these authors tested the effects of $1 \mu \mathrm{M} 2 \mathrm{ME}$ on the MCF-7 breast cancer cell line and the esophageal carcinoma WHCO3 cell line respectively $[44,45]$. In comparing results obtained after 24 hours by $1 \mu \mathrm{M}, 5 \mu \mathrm{M}$ and $10 \mu \mathrm{M} 2 \mathrm{ME}$ and $0.2 \mu \mathrm{M}$ ESE-16 used in this study, the increased potency of ESE-16 can be observed.

ESE-16 has a similar mechanism to that of $2 \mathrm{ME}$, its source compound, and thus also binds to the colchicine binding site situated between the $\alpha$ - and $\beta$-dimers of the tubulin protein $[8,9,14,17,18]$. It was hypothesized that ESE-16 would, like its source compound, cause abnormal spindle formation and activate the SAC, causing metaphase arrest. This would lead to the inhibition of cell proliferation and cell death. Qualitative and quantitative data obtained in this study indicate that ESE-16 blocks the cells in metaphase.

$H \& E$ images revealed hypercondensed chromatin in the ESE-16-treated cells when compared to the appropriate controls. Mitotic indices revealed a significant increase, with a $P$-value of $0.0003^{*}$, in the percentage of cells in metaphase in the ESE-16-treated samples when compared to the controls. The observed effect of ESE-16 on the microtubules was qualitatively confirmed via confocal microscopy, which also showed hypercondensed chromatin and abnormal spindle formation in the ESE-16treated cells when compared to the appropriate controls.

$2 \mathrm{ME}$ has been shown to cause metaphase block in a variety of cell lines (including the MCF-7 cell line, the EC9706 cell line, the WHCO3 cell line and the MDAMB-435 breast cancer cell line) at concentrations of $1 \mu \mathrm{M}, 2 \mu \mathrm{M}, 5 \mu \mathrm{M}$ and $10 \mu \mathrm{M}$ after 24 hours of exposure $[7,19,44,45]$. The increased potency of ESE-16 can once again be seen, since it was able to cause metaphase block in the SNO cell line after 24 hours' exposure at a much lower concentration of $0.2 \mu \mathrm{M}$.

The mitochondria's role in the regulation of cell death is well established [40] and is considered to be the central death machinery in the intrinsic apoptotic pathway [35,46-48], with the key step believed to be mitochondrial membrane permeabilization (MMP) [2,41,46-48].

The possible effect that ESE-16 had on the mitochondria of the SNO cells after exposure was studied by means of flow cytometry by quantitatively analyzing $\Delta \Psi \mathrm{m}$ and ROS production in the SNO cells after ESE16 exposure.

Results obtained from studying the $\Delta \Psi \mathrm{m}$ showed a statistcally significant ( $P$-value of 0.019$)^{*}$ increase in the MFI in the ESE-16-treated cells when compared to the vehicle control. These findings illustrate that ESE-16 caused a decrease in $\Delta \Psi \mathrm{m}$, which may have led to the degradation of the mitochondrial membrane and apoptosis. Since MMP of the mitochondria is considered a key step in the intrinsic apoptotic pathway [2,41,46-48], these results provide evidence of apoptosis taking place via the hypothesized pathway.

The decrease of $\Delta \Psi \mathrm{m}$ due to ESE-16 exposure was also found by Stander et al. in the tumorigenic MCF-7 and MDA-MB-231 cell lines. In addition, Stander et al. showed that ESE-16 had a more pronounced effect on the tumorigenic cell lines when compared to the nontumorigenic MCF-12 cell line [29]. The difference in effects shows possible selectivity of ESE-16 toward the more malignant cell lines when compared to non-malignant cell lines.

The mitochondria are both the major source of intracellular ROS and, at the same time, targets of ROS $[38,39,48]$. ROS are natural by-products from the production of ATP, which occurs in the mitochondrial matrix via the oxidative phosphorylation pathway $[38,40,49,50]$. The accumulation of ROS may lead to oxidative damage to mitochondrial proteins and DNA, causing loss of electron transport, decrease in ATP production and $\Delta \Psi \mathrm{m}$ dissipation $[39,40]$.

Since $\mathrm{O}_{2}{ }^{-}$can be regarded as the precursor for most ROS [40], the levels of $\mathrm{O}_{2}{ }^{-}$were measured via flow cytometry in the SNO cells after ESE-16 exposure. Results revealed an increase in $\mathrm{O}_{2}{ }^{-}$levels in the ESE16-treated cells when compared to the relevant controls. This increase shows that ESE-16 causes oxidative stress after 24 hours' exposure and confirms previously discussed results of $\Delta \Psi \mathrm{m}$ dissipitation, since it is believed that ROS can cause $\Delta \Psi \mathrm{m}$ dissipation $[39,40]$. In addition, ROS accumulation is also believed to act as signaling molecules, which may initiate MMP via the permeability transition pore (PTP), causing the release of the pro-apoptotic proteins found in the intermembrane space $[39,51]$.

Several studies have linked $2 \mathrm{ME}$ with the increase in ROS production, specifically $\mathrm{O}_{2}{ }^{-}$[6,37]. Chua et al. showed, however, that $2 \mathrm{ME}$ induced only a moderate increase in cellular superoxide while analogues of $2 \mathrm{ME}$ extended stronger ROS production, thus suggesting that ROS induction is not a major mechanism of action for $2 \mathrm{ME}$ [6]. This correlates with the Stander et al. paper of 2010, which showed that 2ME-treated MCF-7 cells had no significant increase in $\mathrm{O}_{2}^{-}$levels compared to the vehicle control [44]. By studying various analogues of $2 \mathrm{ME}$, Chua et al. suggest that the 2-methoxy group at position 2 in the $2 \mathrm{ME}$ compound structure is not required for ROS production and may even have an inhibitory effect [6]. In addition, Chua et al. show an increase in $\mathrm{O}_{2}{ }^{-}$levels due to $2 \mathrm{ME}$ analogues that had modifications done on positions 3 and 17 [6]. The increased $\mathrm{O}_{2}{ }^{-}$ production due to ESE-16 might be due to the conformational changes in the ESE-16 compound structure.

After the key step in the intrinsic pathway, believed to be MMP [2,41,46-48], several pro-apoptotic proteins, 
such as AIF and cytochrome $c$, are released into the cytosol [46-48,52-54]. Once released, cytochrome $c$ binds to Apaf-1, allowing deoxyadenosine triphosphate (dATP) to bind onto Apaf-1; inducing conformational changes and causes the oligomerization of Apaf-1 into the Apaf1 apoptosome [35,46-48,53,54]. This apoptosome subsequently recruits and activates the initiator procasapase 9, which in turn activates downstream effector caspases such as caspase 3, leading to the execution phase of apoptosis [35,46-48,53,54].

Caspase activity in the SNO cells after exposure to ESE-16 was quantitatively studied via spectrophotometry. Results revealed a statistically insignificant $(P$-value of 0.238 ) increase in caspase 9 activity in ESE-16-treated cells when compared to the relevant controls. In comparison, caspase 3 results showed a statistically significant increase in activity with a $P$-value of $0.004^{*}$ in the ESE-16-treated cells when compared to the appropriate controls. The difference in the increase of activity of the two caspases might be explained by the fact that the effector caspase 3 had already, at the time of measurement, begun the degradation phase of apoptosis $[35,41]$ and caused a decrease in caspase 9 levels. The caspase activity results show that ESE-16 causes the activation of caspases and induces cell death in a caspasedependent manner.

\section{Conclusion}

This was the first study conducted to investigate the action mechanism of the ESE-16 compound on an esophageal carcinoma cell line. In addition to obtaining information of the action mechanism of ESE-16, this study confirmed the increased potency of this compound compared to its source compound, $2 \mathrm{ME}$.

From this study, it can be concluded that the novel in silico-designed compound induces cell death at a concentration of $0.2 \mu \mathrm{M}$, with an exposure time of 24 hours, in the esophageal carcinoma SNO cell line by disrupting microtubule function. This study unraveled the action mechanism of this novel compound and provides cellular targets for future in vivo studies to establish the counpound's efficacy as a clinically usable anticancer agent. Future studies will investigate the action mechanism of this compound on areas such as angiogenesis; will test whether it exerts any significant side effects and test whether the in silico-design has increased the compounds' bioavailability.

\section{Materials and methods}

\section{Esophageal carcinoma cell line}

SNO esophageal carcinoma cells are non-keratinizing squamous epithelial cells [55] and were purchased from Highveld Biological (Pty) Ltd (Sandringham, SA). The cell line was derived from a well-differentiated squamous cell carcinoma, $6.5 \mathrm{~cm}$ in length and metastatic to the lymph nodes, from a Zulu male aged 62 in 1976 [55].

\section{In silico-designed compound}

The unique, non-commercially available ESE-16 compound was in silico-designed with the use of the Chimera package from the Resource for Biocomputing, Visualization and Informatics at the University of California, San Francisco (supported by NIH P41 RR-01081), which was used for structure preparation and visualization of the compound [8]. Docking studies were carried out with Autodock 4.0 and AutoDockTools4 (Scripps Research Institute, La Jolla, CA, USA) [8]. The ESE-16 compound was synthesized by iThemba Pharmaceuticals (Pty) Ltd (Modderfontein, Gauteng, SA).

\section{General laboratory reagents and supplies}

Dulbecco's Modified Eagle Medium (DMEM) and F-12 Nutrient Mixture, formulated from single-cell plating of Chinese Hamster Ovary (CHO) cells (HAM's-F12), was obtained from Sigma-Aldrich Co. (St. Louis, USA). Penicillin, streptomycin, fungizone, gentamycin and trypsin were obtained from Highveld Biological (Pty) Ltd (Sandringham, SA). Phosphate-buffered saline (PBS) was purchased from Gibco-BRL (Invitrogen, Carlsbad, CA, USA). Dimethyl sulphoxide (DMSO), trypan blue, RNase A, Bouin's fixative and actinomycin D was purchased from Sigma-Aldrich Co. (St Louis, USA). Ethanol was purchased from Merck (Darmstadt, Germany). Fetal calf serum (FCS), sterile cell culture flasks, cell culture plates and syringe filters $(0.22 \mu \mathrm{M})$ were obtained from Separation Scientific (Randburg, SA). Haematoxylin, eosin, ethanol and xylol were purchased from Merck (Darmstadt, Germany). Alpha-tubulin antibody, alexafluor 488, DAPI and the Mitotracker kit was purchased from Biocom Biotech Pty Ltd. (Clubview, SA). The Annexin V-FITC Apoptosis Detection Kit and the Caspase 3 and - 9 Colorimetric Kits were purchased from BioVision (Mountain View, California, USA).

\section{Experimental procedures}

Experiments were conducted at a concentration of $0.2 \mu \mathrm{M}$ with a 24-hour seeding time to allow for attachment and a 24-hour exposure time in a humidified atmosphere $\left(37^{\circ} \mathrm{C}\right.$ with $\left.5 \% \mathrm{CO}_{2}\right)$. A stock solution of 10 mM ESE-16 was dissolved in DMSO and diluted with medium to the desired concentration prior to exposure of the cells. The concentration of $0.2 \mu \mathrm{M}$ for ESE-16 was chosen, since previous dose-dependent investigations conducted in our laboratory showed ESE-16 inhibiting cell proliferation to $50 \%$ from concentrations ranging from $0.18 \mu \mathrm{M}$ to $0.22 \mu \mathrm{M}$ [8].

Experiments were conducted in 6-well plates or $25 \mathrm{~cm}^{2}$ cell culture flasks. For 6 -well plates, cells were 
seeded on heat-sterilized coverslips at a density of $5 \times$ $10^{5}$ cells per well in $3 \mathrm{ml}$ of medium. For $25 \mathrm{~cm}^{2}$ cell culture flasks, cells were seeded at $1 \times 10^{6}$ cells in $5 \mathrm{ml}$ of medium.

Appropriate controls were included: cells propagated in complete medium only, a vehicle control that was composed of cells treated with DMSO, the final dilution never exceeding $0.02 \%(\mathrm{v} / \mathrm{v})[15,56]$. Actinomycin D $(0.1 \mu \mathrm{g} / \mathrm{ml}$ in growth medium) was used as a positive control for the induction of apoptosis [56].

\section{Light microscopy}

\section{Haematoxylin and eosin staining}

$H \& E$ staining allows for the quantitative comparison of the morphological characteristics of the cytoplasm and nuclear components [10]. Hematoxylin has a deep bluepurple color and stains nucleic acids while eosin is pink and stains proteins nonspecifically [57]. Thus, during a general $H \& E$ staining experiment, the nuclei of the cells are stained blue, whereas the cytoplasm and extracellular matrix are stained varying degrees of pink [57]. In order to obtain quantitative data from the morphological study, mitotic indices were determined as described above [10].

SNO cells were seeded in complete growth medium at $5 \times 10^{5}$ cells per well in 6 -well plates on heat-sterilized coverslips. Cells were exposed to ESE-16 and the appropriate controls. After the 24-hour incubation period, coverslips were removed from the wells and transferred to a staining dish. Bouin's fixative was added to the staining dish until the entire sample slide was covered. Samples were incubated at room temperature for $30 \mathrm{~min}$ after which the Bouin's fixative was replaced with $70 \%$ ethanol for $20 \mathrm{~min}$ to dehydrate the cells. Excess fixative was removed and the staining dish was rinsed with tap water to remove excess ethanol. Haematoxylin was added and the samples were incubated at room temperature for $20 \mathrm{~min}$. The staining dish was rinsed with tap water for 2 min and then rinsed with $70 \%$ ethanol to remove any excess stain. Eosin (1\%) was added to the staining dish and samples were incubated at room temperature for $2 \mathrm{~min}$. The staining dish was rinsed twice for $5 \mathrm{~min}$ with $70 \%$ ethanol, twice for $5 \mathrm{~min}$ with $96 \%$ ethanol, twice for $5 \mathrm{~min}$ with $100 \%$ ethanol and twice for $5 \mathrm{~min}$ with xylol. Coverslips were mounted on microscope slides with resin and left overnight to dry. Samples were evaluated at a magnification of $\times 20$ with Zeiss Axiovert MRc microscope (Zeiss, Oberkochen, Germany).

\section{Electron microscopy}

\section{Transmission electron microscopy}

TEM allows a beam of coherent electrons to be directed onto a sample under vacuum [58]. Owing to the scattering of electrons within the sample, small objects inside the cell can be viewed directly [58]. This allows for the study and subsequent better understanding of biological structure-function relationships at cellular, subcellular and molecular levels [58-60]. TEM was used to provide precise intracellular information on the SNO cells.

SNO cells were seeded in complete growth medium at $1.5 \times 10^{6}$ cells per $25 \mathrm{~cm}^{2}$ flask and were subsequently exposed to ESE-16 and the appropriate controls. After the 24-hour incubation period, cells were trypsinized and the samples were resuspended in $1 \mathrm{ml}$ DMEM complete medium. Samples were fixed with PBS:2.5\% gluteraldehyde (9:1) solution for $45 \mathrm{~min}$ at room temperature and then rinsed three times for 5 min each with PBS. Samples were fixed again with osmium tetroxide for $15 \mathrm{~min}$ and rinsed afterwards three times for $5 \mathrm{~min}$ each with PBS. The samples were dehydrated with increasing ethanol concentrations (30\%, 50\%, 70\%, 90\%, 100\%) and left overnight in $100 \%$ ethanol. Samples were then infiltrated and embedded with 100\% EMBED 812. Ultrathin sections of the samples were prepared using a microtome and were contrasted using 4\% uranyl acetate for $5 \mathrm{~min}$ and Reynolds' lead citrate for $2 \mathrm{~min}$, then rinsed with water and viewed at a scale bar of between 2-10 $\mu \mathrm{m}$ with a Multi-purpose Philips 301 TEM (Electron Microscopy Unit, University of Pretoria, South Africa).

\section{Confocal microscopy \\ Confocal-alpha (a)-tubulin assay}

A confocal microscope creates sharp images by performing point-by-point image construction by focusing a point of light sequentially across a specimen, excluding most of the light from the specimen that is not from the microscope's focal plane [61]. Confocal microscopy was employed to observe the effects of ESE-16 on the microtubule tubulin dynamics of SNO cells after 24 hours' exposure time.

SNO cells were seeded in complete growth medium at $5 \times 10^{5}$ cells in 6 -well plates on heat-sterilized coverslips and exposed to ESE-16 and the appropriate controls. After the 24-hour incubation period the samples were fixed with $1.5 \mathrm{ml}$ glutaraldehyde fixer for $10 \mathrm{~min}$ at $37^{\circ} \mathrm{C}$ and then permeabilized with $2 \mathrm{ml}$ permeabilization buffer for $15 \mathrm{~min}$ at room temperature. Samples were stained first with a $100 \mu \mathrm{l}$ mouse monoclonal antibody against human $\alpha$-tubulin (Clone 2-28-33; 1:1000) for 1.5 hours at $37^{\circ} \mathrm{C}$. After the incubation period, samples were washed with PBS for $5 \mathrm{~min}$ at room temperature and then stained with a secondary antibody (biotin-conjugated anti-mouse IgG 58) in FITC-conjugate diluent $(100 \mu \mathrm{l})$, for 1.5 hours at $37^{\circ} \mathrm{C}$. After three 5 min washes with PBS, coverslips were stained with DAPI (2 ml), a nucleic stain that produces blue fluorescence for $10 \mathrm{~min}$ 
at room temperature. Samples were mounted with a glycerol-based mounting fluid on glass slides and viewed with a Zeiss LSM 510 META confocal laser microscope at the Electron Microscopy Unit at the University of Pretoria (Pretoria, South Africa). Images taken by the microscope were visualized at $10 \mu \mathrm{m}$ with the use of ZEN 2009 software (Carl Zeiss (Pty) Ltd Johannesburg, South Africa).

\section{Flow cytometry}

\section{Apoptosis-detection assay}

One of the earliest indications of apoptosis is the translocation of PS from the inner- to the outer leaflet of the plasma membrane where it becomes exposed $[8,62]$. Annexin $\mathrm{V}$ is a $\mathrm{Ca}^{2+}$-dependent phospholipid binding protein with a high affinity for PS $[35,53,59]$ and is used when conjugated to a fluorochrome (FITC) as an indicator of early apoptosis $[8,62]$.

SNO cells were seeded in complete growth medium at $1 \times 10^{6}$ cells per $25 \mathrm{~cm}^{2}$ flasks and were exposed to ESE16 and the appropriate controls. Samples were trypsinized, resuspended in $1 \mathrm{ml} 1 \mathrm{x}$ Binding Buffer and centrifuged at $300 \times \mathrm{g}$ for $10 \mathrm{~min}$. Supernatant was removed and samples were resuspended in $100 \mu \mathrm{l}$ of the $1 \mathrm{x}$ Binding Buffer. Subsequently, $10 \mu \mathrm{l}$ of Annexin V-FITC was added and samples were incubated for $15 \mathrm{~min}$ in the dark at room temperature. After incubation, samples were washed with $1 \mathrm{ml} 1 \mathrm{x}$ Binding Buffer and centrifuged at $300 \times g$ for $10 \mathrm{~min}$. Supernatant was carefully pipetted off and samples were resuspended in $500 \mu \mathrm{l}$ 1x Binding Buffer solution. The FL1 channel was used to measure Annexin V-FITC fluorescence and was conducted with an fluorescence-activated cell sorting (FACS) FC500 system flow cytometer (Beckman Coulter South Africa (Pty) Ltd) equipped with an air-cooled argon laser with an excitation wavelength of $488 \mathrm{~nm}$.

\section{Mitochondrial membrane potential}

The Mitotracker kit allows us to measure the $\Delta \Psi \mathrm{m}$ by labelling the mitochondria with a cationic dye named " $5,5^{\prime}, 6,6$ '-tetrachloro-1,133'-tetra-ethylbenzimidazolylcarbocyanine iodide", which passively diffuses across the plasma membrane and accumulate in active mitochondria providing red fluorescence [36]. However, if there is a reduction in $\Delta \Psi \mathrm{m}$, the dye cannot aggregate in the mitochondria and thus remains in the cytoplasm in its monomer form, generating green fluorescence [36].

SNO cells were seeded at $1 \times 10^{6}$ cells per $25 \mathrm{~cm}^{2}$ flask and exposed to ESE-16 and the appropriate controls. Samples were trypsinized and centrifuged at $13000 \times \mathrm{g}$ and the supernatant was removed. Samples were resuspended in $1 \mathrm{ml}$ diluted Mitocapture solution and incubated at $37^{\circ} \mathrm{C}$ for $20 \mathrm{~min}$. Samples were centrifuged at $500 \times \mathrm{g}$, the supernatant was removed and was resuspended in $1 \mathrm{ml}$ pre-warmed $\left(37^{\circ} \mathrm{C}\right)$ incubation buffer. Samples were analysed using an FACS FC500 System flow cytometer equipped with an air-cooled argon laser excited at $488 \mathrm{~nm}$ (Beckman Coulter South Africa (Pty) Ltd). Apoptotic cells were detected in the FL1 FITC channel showing diffused green fluorescence. Healthy cells were detected in the FL2 channel showing red fluorescence.

\section{Reactive oxygen species}

In the mitochondria, ROS is generated via the electron transport chain and can accumulate as by-products, which can lead to mitochondrial proteins and mitochondrial DNA, causing loss of electron transport, decrease in ATP production and $\Delta \Psi \mathrm{m}$ dissipation [37-40]. In addition, ROS accumulation is believed to act as signaling molecules which initiates MMP, causing the release of pro-apoptotic proteins $[39,51]$. Suspected $\mathrm{O}_{2}{ }^{-}$generation was assessed using $\mathrm{HE}$, an $\mathrm{O}_{2}{ }^{-}$-sensitive dye that is oxidized by $\mathrm{O}_{2}^{-}$to a red fluorescing compound [21,39].

SNO cells were seeded in complete growth medium at $1 \times 10^{6}$ cells per $25 \mathrm{~cm}^{2}$ flask and exposed to ESE-16 and the appropriate controls. Cells were trypsinized and resuspended in $1 \mathrm{ml}$ PBS. Samples were resuspended in $10 \mu \mathrm{M} \mathrm{HE}$ for $15 \mathrm{~min}$ at $37^{\circ} \mathrm{C}$. Fluorescence was measured on the FL2 channel of an FACS FC500 System flow cytometer (Beckman Coulter South Africa (Pty) Ltd equipped with an air-cooled argon laser with an excitation wavelength of $488 \mathrm{~nm}$.

\section{Spectrophotometry Caspase activity}

The activity of caspase 9 and -3 as a result of ESE-16exposure was investigated with the use of a Caspase 9 and -3 Colorimetric Kit. The assays were based on the detection of the chromophore $p$-nitroanilide $(p \mathrm{NA})$ at a wavelength of $405 \mathrm{~nm}$ via spectrophotometry.

SNO cells were seeded in complete growth medium at $1 \times 10^{6}$ cells per $25 \mathrm{~cm}^{2}$ flask and exposed to ESE-16 and the appropriate controls. Cells were trypsinized and centrifuged at $250 \times \mathrm{g}$ for $10 \mathrm{~min}$. Supernatant was removed and samples were lysed with the addition of cold lysis buffer and were incubated on ice for $10 \mathrm{~min}$. Samples were centrifuged at $10000 \times \mathrm{g}$ for $1 \mathrm{~min}$ and supernatant was transferred to new tubes and kept on ice. This was expected to yield a cell lysate with an approximate protein concentration of $2-4 \mathrm{mg} / \mathrm{ml}$. Cell lysate $(50 \mu \mathrm{l})$ were added to wells in a 96-well plate. $2 \times$ Reaction Buffer $(50 \mu \mathrm{l})$ containing dithiothreitol (DDT) stock was added to samples along with $5 \mu \mathrm{l}$ of caspase-3/-9 colorimetric substrate. The plate was incubated at $37^{\circ} \mathrm{C}$ for $1-2$ hours. Absorbance was determined at a wavelength of $405 \mathrm{~nm}$ with the use of an $\mathrm{EL}_{\mathrm{x}} 800$ Universal Microplate Reader (Bio-Tek Instruments Inc. Vermont, USA). 


\section{Statistical analysis}

Qualitative analysis was obtained via light microscopy, confocal microscopy and TEM. Quantitative analysis was obtained via mitotic indices, flow cytometry and spectrophotometry. All experiments conducted were repeated three times. For the techniques that involved flow cytometry, 10000 to 30000 events were counted for each repeat and analysis of the data was done with the use of the Cyflogic program, version 1.2.1, created by Perttu Terho and Mika Korkeamäki from CyFlo Ltd. based in Finland. Quantitative data were analysed for significance by using student $t$-test statistics. A $P$-value of $<0.05$ was regarded as statistically significant.

\begin{abstract}
Abbreviations
2ME: 2-Methoxyestradiol; $\Delta \psi \mathrm{m}$ : Mitochondrial membrane potential; Apaf-1: Apoptotic protease activating factor 1; ATP: Adenosine triphosphate: CAll: Carbonic anhydrase II; CAIX: Carbonic anhydrase IX; CHO: Chinese Hamster Ovary; DAPI: 4',6-Diamidino-2-phenylindole; dATP: Deoxyadenosine triphosphate; DDT: Dithiothreitol; DMEM: Dulbecco's modified eagle medium; DMSO: Dimethyl sulphoxide; DNA: Deoxyribonucleic acid; EA: Esophageal adenocarcinoma; EC: Esophageal cancer; ESCC: Esophageal squamous cell carcinoma; ESE-16: 2-Ethyl-3-O-sulphamoyl-estra-1,3,5(10)16-tetraene; FACS: Fluorescence-activated cell sorting; FCS: Fetal calf serum; FITC: Fluorescein isothiocyanate; H\&E: Haematoxylin and eosin; MFI: Mean fluorescent intensity; MMP: Mitochondrial membrane permeabilization; MIDs: Microtubule-interfering drugs; $\mathrm{NAD}^{+}$: Nicotinamide adenine dinucleotide; NADH: Reduced nicotinamide adenine dinucleotide; $\mathrm{NADP}^{+}$ Nicotinamide adenine dinucleotide phosphate; NADPH: Reduced nicotinamide adenine dinucleotide phosphate; NCD: Nanocrystal dispersion; $\mathrm{O}_{2}^{-}$: Superoxide; PBS: Phosphate buffered saline; PS: Phosphatidylserine; PTP: Permeability transition pore; ROS: Reactive oxygen species; SAC: Spindle assembly checkpoint; TEM: Transmission electron microscopy.
\end{abstract}

\section{Competing interests}

The authors declare that they have no competing interests.

\section{Authors' contributions}

EW conducted all experiments, analyzed the data and drafted the manuscript. KS and RM helped with the design of the study. AJ designed the study and helped with data analysis and the drafting of the manuscript. All authors read and approved the final manuscript.

\section{Acknowledgements}

The authors are grateful to the Department of Pharmacology, University of Pretoria, South Africa for the use of their flow cytometer and to the Electron Microscopy Unit, University of Pretoria, South Africa, for the use of the transmission electron microscope. Barbara English of the research office of the University of Pretoria's Faculty of Health Sciences is thanked for language editing.

This study was supported by grants from the Medical Research Council of South Africa, the Cancer Association of South Africa, Research Committee of the University of Pretoria (RESCOM), the National Research Foundation (NRF), the Institute for Cellular and Molecular Medicine (ICMM) and and the Struwig- Germeshuysen Cancer Research Trust of South Africa.

\section{Author details}

'Department of Physiology, University of Pretoria, Pretoria, South Africa. ${ }^{2}$ Department of Biochemistry and Molecular Biology, Baylor College of Medicine, Houston, Texas, USA. ${ }^{3}$ McKnight Institute, University of Florida, Gainesville, Florida, USA.

Received: 21 July 2014 Accepted: 2 November 2014

Published: 20 November 2014

\section{References}

1. Zhou J, Giannakakou P: Targeting microtubules for cancer chemotherapy. Curr Med Chem Anticancer Agents 2005, 5:65-71.

2. Rovini A, Savry A, Braguer D, Carre M: Microtubule-targeted agents: when mitochondria become essential to chemotherapy. Biochim Biophys Acta 1807, 2011:679-688.

3. Calligaris D, Verdier-Pinard P, Devred F, Villard C, Braguer D, Lafitte D: Microtubule targeting agents: from biophysics to proteomics. Cell Mol Life Sci 2010, 67:1089-1104.

4. Luch A: Cell cycle control and cell division: implications for chemically induced carcinogenesis. Chembiochem 2002, 3:506-516.

5. Mollinedo F, Gajate C: Microtubules, microtubule-interfering agents and apoptosis. Apoptosis 2003, 8:413-450.

6. Chua YS, Chua YL, Hagen T: Structure activity analysis of 2-methoxyestradiol analogues reveals targeting of microtubules as the major mechanism of antiproliferative and proapoptotic activity. Mol Cancer Ther 2010, 9:224-235.

7. Du B, Zhao Z, Sun H, Ma S, Jin J, Zhang Z: Effects of 2-methoxyestradiol on proliferation, apoptosis and gene expression of cyclin B1 and c-Myc in esophageal carcinoma EC9706 cells. Cell Biochem Funct 2012, 30:158-165

8. Stander A, Joubert F, Joubert A: Docking, synthesis, and in vitro evaluation of antimitotic estrone analogs. Chem Biol Drug Des 2011, 77:173-181.

9. Kamath K, Okouneva T, Larson G, Panda D, Wilson L, Jordan MA: 2-Methoxyestradiol suppresses microtubule dynamics and arrests mitosis without depolymerizing microtubules. Mol Cancer Ther 2006, 5:2225-2233.

10. Van Zill C, Lottering ML, Steffens F, Joubert A: In vitro effects of 2-methoxyestradiol on MCF-12A and MCF-7 cell growth, morphology and mitotic spindle formation. Cell Biochem Funct 2008, 26:632-642.

11. Voster CJ, Joubert AM: In vitro effects of 2-methoxyestradiol-bis-sulphamate on the non-tumorigenic MCF-12A cell line. Cell Biochem Funct 2010, 28:412-419.

12. Joubert A, Marais $\mathrm{S}$ : Influence of 2-methoxyestradiol on cell morphology and Cdc2 kinase activity in WHCO3 esophageal carcinoma cells. Biomed Res 2007, 28:9-16.

13. Newman SP, Ireson CR, Tutill HJ, Day JM, Parsons MF, Leese MP, Potter BVL, Reed MJ, Purohit A: The role of 17beta-hydroxysteroid dehydrogenases in modulating the activity of 2-methoxyestradiol in breast cancer cells. Cancer Res 2006, 66:324-330.

14. Zhu BT, Conney AH: Is 2-methoxyestradiol an endogenous estrogen metabolite that inhibits mammary carcinogenesis? Cancer Res 1998, 58:2269-2277.

15. Joubert A, Maritz C, Joubert F: Bax/BCl-2 expression levels of 2-methoxyestradiolexposed esophageal cancer cells. Biomed Res 2005, 26:131-134.

16. Joubert A, Marais S: In vitro effects of 2-methoxyestradiol on cell morphology and Cdc2 Kinase activity in SNO oesophageal carcinoma cells. Cell Biochem Funct 2007, 25:357-362.

17. Mooberry SL: Mechanism of action of 2-methoxyestradiol: new developments. Drug Resist Updat 2003, 6:355-361.

18. Downing KH: Structural basis for the interaction of tubulin with proteins and drugs that affect microtubule dynamics. Annu Rev Cell Dev Biol 2000 16:89-111.

19. Choi HJ, Zhu BT: Critical role of cyclin B1/Cdc2 up-regulation in the induction of mitotic prometaphase arrest in human breast cancer cells treated with 2-methoxyestradiol. Biochim Biophys Acta 1823, 2012:1306-1315.

20. Purohit A, Hejaz HA, Walden L, MacCarthy-Morrogh L, Packham G, Potter BV Reed MJ: The effect of 2-methoxyoestrone-3-O-sulphamate on the growth of breast cancer cells and induced mammary tumours. Int J Cancer 2000, 85:584-589.

21. Visagie $M H$, Joubert AM: In vitro effects of 2-methoxyestradiol-bissulphamate on reactive oxygen species and possible apoptosis induction in a breast adenocarcinoma cell line. Cancer Cell Int 2011, 11:43-49.

22. Liu Q, Jin W, Zhu Y, Zhou J, Lu M, Zhang Q: Synthesis of 3'-methoxyE-diethylstilbestrol and its analogs as tumor angiogenesis inhibitors. Steroids 2012, 77:419-423.

23. Tevaarwerk AJ, Holen KD, Alberti DB, Sidor C, Arnott J, Quon C, Wilding G, Liu G: Phase I trial of 2-methoxyestradiol NanoCrystal dispersion in advanced solid malignancies. Clin Cancer Res 2009, 15:1460-1465.

24. Matei D, Schilder J, Sutton G, Perkins S, Breen T, Quon C, Sidor C: Activity of 2 methoxyestradiol (Panzem NCD) in advanced, platinum-resistant 
ovarian cancer and primary peritoneal carcinomatosis: a Hoosier Oncology Group trial. Gynecol Oncol 2009, 15:90-96.

25. Harrison MR, Hahn NM, Pili R, Oh WK, Hammers H, Sweeney C, Kim KM, Perlman S, Arnott J, Sidor C, Wilding G, Liu G: A phase II study of 2-methoxyestradiol (2ME2) NanoCrystal(R) dispersion (NCD) in patients with taxane-refractory, metastatic castrate-resistant prostate cancer (CRPC). Invest New Drugs 2011, 29:1465-1474.

26. Bruce JY, Eickhoff J, Pili R, Logan T, Carducci M, Arnott J, Treston A, Wilding G, Liu G: A phase II study of 2-methoxyestradiol nanocrystal colloidal dispersion alone and in combination with sunitinib malate in patients with metastatic renal cell carcinoma progressing on sunitinib malate. Invest New Drugs 2012, 30:794-802.

27. Leese MP, Leblond B, Newman SP, Purohit A, Reed MJ, Potter BV: Anti-cancer activities of novel D-ring modified 2-substituted estrogen-3-O-sulfamates. J Steroid Biochem Mol Biol 2005, 94:239-251.

28. Chander SK, Foster PA, Leese MP, Newman SP, Potter BV, Purohit A, Reed $\mathrm{MJ}$ : In vivo inhibition of angiogenesis by sulphamoylated derivatives of 2-methoxyoestradiol. Br J Cancer 2007, 96:1368-1376.

29. Stander BA, Joubert F, Tu C, Sippel KH, McKenna R, Joubert AM: Signaling pathways of ESE-16, an antimitotic and anticarbonic anhydrase estradiol analog, in breast cancer cells. PLoS One 2013, 8:e53853-e53868.

30. Theron AE, Nolte EM, Lafanechere L, Joubert AM: Molecular crosstalk between apoptosis and autophagy induced by a novel 2methoxyestradiol analogue in cervical adenocarcinoma cells. Cancer Cell Int 2013, 13:87-105.

31. Nkandeu DS, Mqoco TV, Visagie MH, Stander BA, Wolmarans E, Cronje MJ, Joubert AM: In vitro changes in mitochondrial potential, aggresome formation and caspase activity by a novel 17-beta-estradiol analogue in breast adenocarcinoma cells. Cell Biochem Funct 2013, 31:566-574

32. Wolmarans E, Mqoco TV, Stander A, Nkandeu SD, Sippel K, McKenna R, Joubert A: Novel estradiol analogue induces apoptosis and autophagy in esophageal carcinoma cells. Cell Mol Biol Lett 2014, 19:98-115.

33. Visagie $M$, Mqoco $T$, Joubert A: Sulphamoylated estradiol analogue induces antiproliferative activity and apoptosis in breast cell lines. Cell Mol Biol Lett 2012, 17:549-558.

34. Visagie $\mathrm{MH}$, Joubert $\mathrm{AM}$ : 2-Methoxyestradiol-bis-sulfamate induces apoptosis and autophagy in a tumorigenic breast epithelial cell line. Mol Cell Biochem 2011, 357:343-352.

35. Blatt NB, Glick GD: Signaling pathways and effector mechanisms pre-programmed cell death. Bioorg Med Chem 2001, 9:1371-1384.

36. Visagie MH, Joubert AM: The in vitro effects of 2-methoxyestradiol-bis-sulphamate on cell numbers, membrane integrity and cell morphology, and the possible induction of apoptosis and autophagy in a non-tumorigenic breast epithelial cell line. Cell Mol Biol Lett 2010, 15:564-581.

37. Chauhan D, Li G, Sattler M, Podar K, Mitsiades C, Mitsiades N, Munshi N, Hideshima T, Anderson KC: Superoxide-dependent and -independent mitochondrial signaling during apoptosis in multiple myeloma cells. Oncogene 2003, 22:6296-6300.

38. Mammucari C, Rizzuto R: Signaling pathways in mitochondrial dysfunction and aging. Mech Ageing Dev 2010, 131:536-543.

39. Murphy MP: How mitochondria produce reactive oxygen species. Biochem J 2009, 417:1-13.

40. Orrenius S, Gogvadze V, Zhivotovsky B: Mitochondrial oxidative stress: implications for cell death. Annu Rev Pharmacol Toxicol 2007, 47:143-183.

41. Brentnall M, Rodriguez-Menocal L, De Guevara RL, Cepero E, Boise LH: Caspase-9, caspase-3 and caspase-7 have distinct roles during intrinsic apoptosis. BMC Cell Biol 2013, 14:32-41.

42. Genis C, Sippel KH, Case N, Cao W, Avvaru BS, Tartaglia LJ, Govindasamy L, Tu C, Agbandje-McKenna M, Silverman DN, Rosser CJ, McKenna R: Design of a carbonic anhydrase IX active-site mimic to screen inhibitors for possible anticancer properties. Biochemistry 2009, 48:1322-1331.

43. Pribluda VS, Gubish ER Jr, Lavallee TM, Treston A, Swartz GM, Green SJ: 2-Methoxyestradiol: an endogenous antiangiogenic and antiproliferative drug candidate. Cancer Metastasis Rev 2000, 19:173-179.

44. Stander BA, Marais S, Vorster CJ, Joubert AM: In vitro effects of 2-methoxyestradiol on morphology, cell cycle progression, cell death and gene expression changes in the tumorigenic MCF-7 breast epithelial cell line. J Steroid Biochem Mol Biol 2010, 119:149-160.

45. Thaver $V$, Lottering $M$, van Papendorp $D$, Joubert $A$ : In vitro effects of 2-methoxyestradiol on cell numbers, morphology, cell cycle progression, and apoptosis induction in oesophagealcarcinoma cells. Cell Biochem Funct 2009, 27:205-210.

46. Movassagh M, Foo RS: Simplified apoptotic cascades. Heart Fail Rev 2008, 13:111-119.

47. Pradelli LA, Beneteau M, Ricci JE: Mitochondrial control of caspase-dependent and -independent cell death. Cell Mol Life Sci 2010, 67:1589-1597.

48. Wu CC, Bratton SB: Regulation of the intrinsic apoptosis pathway by reactive oxygen species. Antioxid Redox Signal 2012, 19:546-558.

49. Kussmaul L, Hirst J: The mechanism of superoxide production by NADH: ubiquinone oxidoreductase (complex I) from bovine heart mitochondria. Proc Natl Acad Sci U S A 2006, 103:7607-7612

50. Giorgio M, Migliaccio E, Orsini F, Paolucci D, Moroni M, Contursi C, Pelliccia G, Luzi L, Minucci S, Marcaccio M, Pinton P, Rizzuto R, Bernardi P, Paolucci F, Pelicci PG: Electron transfer between cytochrome $c$ and p66Shc generates reactive oxygen species that trigger mitochondrial apoptosis. Cell 2005, 122:221-233.

51. Wickman GR, Julian L, Mardilovich K, Schumacher S, Munro J, Rath N, Zander SAL, Mleczak A, Sumpton D, Morrice N, Bienvenut W, Olson MF: Blebs produced by actin-myosin contraction during apoptosis release damage-associated molecular pattern proteins before secondary necrosis occurs. Cell Death Differ 2013, 20:1293-1305.

52. Cregan SP, Dawson VL, Slack RS: Role of AIF in caspase-dependent and caspase-independent cell death. Oncogene 2004, 23:2785-2796.

53. Van Cruchten S, Van den Broeck W: Morphological and biochemical aspects of apoptosis, oncosis and necrosis. Anat Histol Embryol 2002, 31:214-223.

54. Galluzzi L, Zamzami N, de La Motte RT, Lemaire C, Brenner C, Kroemer G: Methods for the assessment of mitochondrial membrane permeabilization in apoptosis. Apoptosis 2007, 12:803-813.

55. Bey E, Alexander J, Whitcutt JM, Hunt JA, Gear JH: Carcinoma of the esophagus in Africans: establishment of a continuously growing cell line from a tumor specimen. In Vitro 1976, 12:107-114

56. Mqoco T, Marais S, Joubert A: Influence of estradiol analogue on cell growth, morphology and death in esophageal carcinoma cells. Biocell 2010, 34:113-120.

57. Fischer AH, Jacobson KA, Rose J, Zeller R: Hematoxylin and eosin staining of tissue and cell sections. CSH Protoc 2008. doi:10.1101/pdb.prot4986.

58. Hurbain I, Sachse M: The future is cold: cryo-preparation methods for transmission electron microscopy of cells. Biol Cell 2011, 103:405-420.

59. Kepp O, Galluzzi L, Lipinski M, Yuan J, Kroemer G: Cell death assays for drug discovery. Nat Rev Drug Discov 2011, 10:221-237.

60. Krysko DV, Vanden Berghe T, D'Herde K, Vandenabeele P: Apoptosis and necrosis: detection, discrimination and phagocytosis. Methods 2008 44:205-221.

61. Semwogerere D, Weeks ER: Confocal microscopy. In Encyclopedia of Biomaterial Biomedical Engineering. Volume 2. Edited by Wnek GE, Bowlin GL. United Kingdom: Taylor and Francis; 2004:1-10.

62. Wlodkowic D, Skommer J, Darzynkiewicz Z: Cytometry of apoptosis. Historical perspective and new advances. Exp Oncol 2012, 34:255-262.

doi:10.1186/2045-3701-4-68

Cite this article as: Wolmarans et al:: Induction of the intrinsic apoptotic pathway via a new antimitotic agent in an esophageal carcinoma cell line. Cell \& Bioscience 2014 4:68

\section{Submit your next manuscript to BioMed Central and take full advantage of:}

- Convenient online submission

- Thorough peer review

- No space constraints or color figure charges

- Immediate publication on acceptance

- Inclusion in PubMed, CAS, Scopus and Google Scholar

- Research which is freely available for redistribution 